\title{
Scoutismo católico en Argentina (1940-1960)
}

\section{Catholic Scouting in Argentina (1940-1960)}

\author{
AdRIÁN CAMMAROTA \\ CONICET, IIEGE, FFyL, UBA \\ Universidad de la Matanza \\ Florencio Varela 190, B1754JEC \\ San Justo, Buenos Aires, Argentina \\ adriancammarota2000@gmail.com \\ KARINA INÉS RAMACCIOTTI \\ CONICET, IIEGE, FFyL, UBA \\ Universidad de Quilmes \\ Roque Sáenz Peña 352, B1876BXD \\ Bernal, Buenos Aires, Argentina \\ karinaramacciotti@gmail.com
}

RESUMEN El objetivo de este artículo es analizar la relación entre la cultura scóutica, el catolicismo y el asociacionismo juvenil entre las décadas de 1940 y 1960 en Argentina. El dinamismo que había cobrado la Iglesia Católica en la década de 1930, con los intentos de "recristianizar" la sociedad y por desmantelar el Estado liberal instaurado en el siglo XIX, encontró sus límites durante las décadas del cuarenta y sesenta. Nos preguntamos qué finalidad tuvieron los campamentos católicos y cuáles fueron los fundamentos y estrategias para ocupar el tiempo libre de los jóvenes en vacaciones $y$, de esta forma, moldear su masculinidad dentro de la moral católica. Cabe señalar que en dicho período las sociabilidades juveniles se encontraban diversificadas y atravesadas por distracciones culturales remozadas como consecuencia de las nuevas estrategias culturales de consumo masivas consideradas perniciosas por el pensamiento católico.

Recibido: 26 dic. 2016 | Revisto por los autores: 16 jun. y 08 ago. 2017

| Aprobado: 10 ago. 2017

http://dx.doi.org/10.1590/0104-87752017000300009

Varia Historia, Belo Horizonte, vol. 33, n. 63, p. 779-806, set/dez 2017 
Palabras-Clave asociacionismo juvenil, scoutismo católico, masculinidad

Abstract The aim of this article is to analyze the relation among the scouting culture, the Catholicism and youngster associationism from 1940 to 1960 in Argentina. The dynamism achieved by the Catholic Church during the 1930s, along with the efforts to dismantle the liberal state established during the 19th century, reached its limits during the 1940 s and 1960s. We wonder what the purpose of Catholic camps was and what the grounds and strategies were to occupy the free time of young people during holidays, and in that way shape their masculinity within the Catholic morale. It is worth highlighting that in such period the social interaction in youngsters was diversified and crossed by cultural distractions, renovated as a result of the new cultural strategies of massive consumption, which the Catholic thinking regarded as harmful. KEYWORDS youngster associationism, scouting Catholicism, masculinity

En abril de 1956 el grupo de jóvenes de la Peña "Los amigos" de la localidad porteña de Monserrat describían, en el libro de actas de dicha asociación, que realizarían un campamento para el verano de 1957 y para solventarlo constituirían un fondo monetario. Las metas serían: organizar un "banquito" con los aportes de los socios; realizar préstamos a los mismos miembros de la asociación cobrando un pequeño interés; efectuar rifas, reuniones sociales y venta de objetos para: "incrementar el capital social; crear cuentas personales para asentar las cuotas abonadas mensualmente; organizar reuniones sociales para recaudar fondos". Posteriormente, se designaría un secretario encargado llevar el control sobre el movimiento de entradas y salidas y dos Revisores de cuentas. También se nombraría una Comisión Directiva compuesta por un presidente y un vicepresidente, un secretario, un tesorero y un vocal.

La asociación tuvo una agenda nutrida con el objetivo de organizar una peña. En el "Rancho" de Biernat - uno de los principales referentes - se realizaron todos los preparativos. Al finalizar la peña se agradeció la 
"deferencia de todos los presentes, haciendo notar el espíritu de verdadera camarería reinante como vínculo de unión entre las familias y conocidos". Otras de las acciones realizadas fueron los bailes y las fiestas de carnaval. Los eventos estaban planificados cuidadosamente: confeccionaban las invitaciones, distribuían cotillón entre los asistentes y diseñaban dibujos sobre las paredes del patio de baile. En el diario se lee "se notó poca animación, debido quizás a la noche fresca, a la falta de selección de discos y a las diversas tareas que hubo que realizar con poco elemento humano". En el segundo baile, según el diario, "se solucionaron los inconvenientes" del primer evento. ${ }^{1}$

Uno de los objetivos era lograr la concreción de un Campamento de Verano. Después de un intercambio de ideas acordaron realizar el programado evento en las sierras de Tandil en la provincia de Buenos Aires. Había sido desechado del programa la ciudad de Mina Clavero (Córdoba) por el compromiso que generaba en la economía de los jóvenes. Los fondos del "banquito" treparon a una suma de dos mil trescientos pesos y fueron destinados a la adquisición de una tela especial para la fabricación de carpas. La Peña "Los Amigos" contó con el consejo del maestro Scout Miguel Ángel García, quien recomendó no elegir ese destino en razón de los costos del pasaje, la duración del viaje y el trastorno que significa trasladar toda la carga. En consecuencia, propuso realizar un campamento más económico.

Por cuestiones laborales los muchachos partieron en dos grupos. Cada uno de los campamentos disponía una cantidad de cuatrocientos pesos. Ante cualquier eventualidad se estableció una clave telegráfica: si encontraban inconvenientes y el regreso era inevitable debían colocar en el telegrama "HAY NUBES". Si, por el contrario, todo se realizaba conforme a lo programado, el texto debía rezar "SIEMPRE LISTOS". El 23 de marzo partió el primer grupo y el 26 el segundo, luego de recibir el telegrama oficioso para la partida. Según se relata en el Acta el viaje se hizo entretenido por el paisaje. En la estación fueron recibidos por el joven Saberio: "con una vestimenta combinada de Scout y de linyera,

1 Peña “Los Amigos", 1957, s/p. 
barba crecida, una boina a lo Montgomery. Nosotros no le quedábamos a la zaga con poderosas mochilas cargadas con pantalón de montar y botas, En fin, fuimos el comentario obligado de los locales y viajeros".

El meticuloso diario del campamento finalizó con la llegada a destino. Una vez logrado el objetivo, en agosto de 1957, los siete integrantes de la Peña presentaron el Estatuto de la Asociación y declamaron sus deseos entre los cuales se destacó la semejanza de la Peña "a un muro y cada uno de sus integrantes a un ladrillo". Fortaleza, integridad y solidaridad se combinaban como características para "La Peña Los Amigos" pero, al mismo tiempo, moldeaban los valores deseados para la masculinidad y, por ende, para la femineidad. Luego, se aprobó el preámbulo del Estatuto por unanimidad: "La Peña Los Amigos", "integrada por aquellos que alienta en sus corazones el fuego de la Juventud y cultivan la Amistad Cristiana".

La Asociación "Los Amigos" tenía una experiencia previa. La mayoría de ellos - en total eran siete integrantes - que militaban en la rama juvenil de la Acción Católica Argentina (ACA), es decir, la Juventud de Acción Católica (JAC). El cuaderno de Actas denota la impronta católica de la organización. Los llamados a la reflexión para no descuidar la vida espiritual y el dogma internalizado en la ACA fueron reiterados; para reforzar los íntimos y fuertes los lazos de amistad cristiana. Ahora bien, ¿qué nos ilustra esta experiencia puntual? ¿Qué fuerzas colectivas y contextuales actuaron como telón de fondo?

Esta experiencia nos sirve como acicate para reflexionar sobre la relación entre la cultura scóutica, el catolicismo y el asociacionismo juvenil a mediados del siglo XX en la Argentina. Es en este sentido que este artículo dialoga con aquellos trabajos que se centraron en el estudio de las relaciones entre la cultura católica dentro de la JAC y la crisis que selló su decrecimiento en los años cuarenta (Acha, 2010, p.27-30). Tal como señala Miranda Lida, durante la década de 1940 y 1950 la Iglesia perdió su dinamismo, y durante los años peronistas los congresos eucarísticos se organizaron a duras penas; la presencia del catolicismo en la radio

2 Peña "Los Amigos", 1957, s/p.

3 Peña "Los Amigos", 1957, s/p. 
se estancó, al igual que el número de diócesis. Ni siquiera, nos dice la investigadora, la legalización de la enseñanza religiosa en 1947 revertió la situación (Lida, 2012, p.04). El dinamismo que había cobrado la Iglesia católica en la década de 1930, con los intentos de "recristianizar" la sociedad y por desmantelar el Estado liberal instaurado en el siglo XIX, encontró sus límites durante las décadas del cuarenta y sesenta. Así pues, en este artículo nos preguntamos cuáles fueron las dinámicas culturales que llevaron a la Iglesia Católica a considerar al scoutismo como un método de disciplinamiento dirigido para disciplinar y alejar a los jóvenes de la sexualidad no controlada, los peligros del crecimiento urbano, la expansión de la industria cinematográfica, considerada perniciosa, y el temor a la alteridad ideológica. Cabe señalar que cuando hablamos de Iglesia católica hacemos referencia tanto a la jerarquía eclesiástica como a determinados organismos capilares dentro de la estructura institucional.

También nos interesa dialogar con la literatura que investiga los espacios de sociabilización juvenil; no solamente los forjados dentro del catolicismo sino también los gestados en los espacios públicos, las escuelas secundarias laicas con los Clubes Colegiales, las sociedades de fomento o los espectáculos deportivos. Estos espacios fueron diversos y las formas de asociacionismo o, mejor dicho, sus mecanismos de integración, se entrecruzaron transformándose en los campos de disputa entre el catolicismo y la tradición liberal del sistema educativo, entre los espacios callejeros y el Estado que veía con peligrosidad la presencia de los jóvenes en las calles sin ocupación fija; o el gobierno peronista que intentó pautar una suerte de asociacionismo político "desde arriba" con la creación de la Unión de Estudiantes Secundarios (UES). Si en algo coincidían esos dispositivos de control que se cernían sobre los jóvenes, fue en la necesidad de acoplarlos en un paradigma que aglutinara las demandadas para el forjamiento del espíritu, el control del cuerpo y los valores morales deseados para varones y mujeres (Blanco, 2011, p.139-160; Cammarota, 2014, p.111). En esta dirección, consideramos que este artículo explora las estructuras discursivas y formativas que cimentaron la militancia de los jóvenes católicos en una de sus variantes: la práctica scout. 
Por último, esta propuesta se nutre de las investigaciones que han iluminado una serie de aspectos entroncados con el scoutismo desde diferentes perspectivas; los procesos de medicalización y cristianización del cuerpo en las escuelas salesianas y en los exploradores de Don Bosco, los vínculos entre el scoutismo y la formación militar en las escuelas moldeadas por la ley 1420 a fines del siglo XIX; la visión que bosquejaron los socialistas en torno al scoutismo y quienes revisan el tema del scoutismo femenino (Scharagrodsky, 2006, p.135-158; Scharagrodsky; Cornelis, 2013; Méndez, 2013; Bisso, 2016).

Así pues, el relato de la experiencia de la Peña "Los Amigos" nos permite preguntarnos sobre las finalidades de los campamentos católicos y cuáles fueron los fundamentos y estrategias para ocupar el tiempo libre de los jóvenes en vacaciones y, de esta forma, moldear su masculinidad a mitad del siglo XX. Los temores por el uso del tiempo libre y el ocio entre la juventud ya habían sido expresados en las décadas previas por un variado arco político y profesional; no obstante en este artículo nos centraremos en el estudio de cómo la JAC abordó lo que era visto como un problema: el tiempo libre entre los jóvenes militantes a mitad del siglo XX y cómo intentar domeñar los desbordes sexuales juveniles por medio de los campamentos.

Para el abordaje de la propuesta nos hemos nutrido de una diversidad de revistas editorializadas por la JAC, boletines internos, Circulares del Consejo Arquidiocesano de Buenos Aires y diarios de campamentos realizados en distintos puntos del país. Este acervo documental variado nos permite señalar tanto las estrategias de la jerarquía eclesiástica como las ideas que circulaban en los espacios nodales del mundo católico. Este corpus nos permite relucir los ámbitos de sociabilidad esbozados por la JAC, la direccionalidad cultural e ideológica del ocio y el tiempo libre. También el trabajo puede aportar a los estudios de género en la medida que en los campamentos scout son de utilidad para lograr una comprensión de la relación entre géneros, sexualidad, moral y normas sociales levantadas como una construcción cultural que se asentó en un ideal de masculinidad $y$, por ende, de femineidad. 


\section{LA JUVENTUD DE ACCIÓN CATÓLICA Y EL SCOUTISMO}

Durante la primera mitad de siglo XX la juventud fue ganando una densidad propia y cobraría relevancia en el mundo de la segunda posguerra, estimulada por las políticas de Estado de Bienestar en Europa y Estados Unidos. Los jóvenes se convirtieron en motivo de inquietud dentro de la agenda de los Estados capitalistas y de los países socialistas. Una de las preocupaciones era el tiempo libre y el deporte, ya que ambos se ligaban al intento de controlar corporal y moralmente en su etapa formativa a la juventud. En Argentina, desde la década de 1930 y hasta la llegada del peronismo al poder en 1946, el tiempo libre de los jóvenes organizado por el Estado estuvo reducido a la diversión comercial y al fomento de las instituciones culturales como bibliotecas y museos. Por su parte, en las escuelas secundarias se alentaba el desarrollo del deporte en consonancia con la idea de mejorar la salud del futuro ciudadano y desplegar determinados valores conectados con las virtudes ciudadanas ligadas con la masculinidad. Así, se institucionalizaron los Clubes Colegiales, que tenían como meta organizar actividades culturales y deportivas. Este proceso se fortaleció durante los años que van de 1940 a 1960 en un periodo en que la expansión del ciclo medio había logrado escolarizar a un sector importante de la población juvenil (Cammarota, 2014).

Durante el peronismo clásico (1946-1955), el Estado intentó articular de manera más organizada el tiempo libre de las masas, fortaleciendo el proceso que venía de las décadas anteriores e interviniendo en tres esferas puntuales: ampliando los resortes materiales del deporte (turf, automovilismo, boxeo, fútbol ), terciando en la industria cinematográfica con censuras y controles, fomentando una serie de actividades recreativas en las unidades básicas del partido y, por último, implementando el "turismo popular" (Scarzanella, 1998, p.68-70). Hay que señalar que uno de los principales benefactores de estos espectáculos de masas fue la juventud. Como ha señalado Anahí Ballent, el peronismo estimuló con un tinte popular el vínculo entre política, esparcimiento y difusión cultural en el espacio público urbano. Por ejemplo, los actos 
políticos solían incluir música clásica y ballet o espectáculos teatrales al aire libre (Ballent, 2006, p.250). Por último, resta señalar que uno de los intentos del gobierno de Perón por direccionar los hábitos y conductas juveniles encontró su experimento más excelso con la creación de un asociacionismo político-juvenil expresado en la UES, creada tardíamente en 1953.

Ahora bien, este escenario descripto subsumió las preocupaciones de la jerarquía católica con respecto a la vida juvenil masculina. Durante la década de 1930 la Iglesia Católica desplegó sus propias estrategias para atraer a los jóvenes a los márgenes doctrinales de la institución, en consonancia con las aspiraciones del integrismo católico y en detrimento de una laicización de la vida cotidiana, identificada como perniciosa para los valores cristianos. Los objetivos del catolicismo integrista eran infiltrarse en el Estado y en el grueso de la sociedad civil. El discurso católico integrista entroncó con una serie de fenómenos característicos de la vida cotidiana en la ciudad moderna (el ocio, el turismo, el consumo, los espectáculos de masas y la política) y alcanzó masividad en este periodo. Sobre este telón de fondo se fundó en 1931 la Acción Católica Argentina y su rama juvenil, la Juventud de Acción Católica (JAC).

El programa de la ACA se definía como la participación del laicado en el apostolado jerárquico de la Iglesia. El desarrollo de la JAC se afirmó sobre al llamado apostolado celular. En virtud de ello, los jóvenes debían obrar como una célula formando parte de un todo orgánico (la JAC). Según el Boletín del Dirigente, publicación editada por la Asociación de los Jóvenes de la Acción Católica, el apostolado organizado debía estar preparado para tres fines específicos: Defensivo (aclarar, contrarrestar y desenmascarar a aquellos que atacaban a la Iglesia); Preventivo (evitando la influencia dañina de las publicaciones y palabra de los enemigos); Conquistador (penetrando en los diversos ambientes - hogares, ámbitos de trabajo, espacios de socialización, distintas clases sociales instruyendo a los individuos y conquistando sus almas. El apostolado apuntaba a conquistar espiritualmente a los individuos que rodeaban al joven en la vida cotidiana, como la familia, el colegio, el club u otros ámbitos de socialización. 
Como centro de irradiación del apostolado, la parroquia y sus secciones constituían la materia prima de la JAC. Las secciones eran pensadas como "Escuelas Militares" donde se instruía a los soldados por voluntad de Dios y el Santo Padre. Como "Cadetes del Ejército de Cristo", se instaba a los jóvenes a vencer la adversidad, la mediocridad de la vida espiritual y la falta de cumplimiento en las tareas asignadas por las secciones. La analogía entre el orden militar y el orden que se pretendía imponer en pos de cristianizar los cuerpos y las mentes no podía ser más correcta. Jerarquía, orden, disciplina reordenaban las subjetividades y las experiencias del sujeto. La terminología castrense se utilizó regularmente para dar cuenta de diversas temáticas y cuestiones referidas a la vida cotidiana de la JAC. Una de las formas de vencer la "debilidad del carácter" y formar el espíritu cristiano fue la internalización de las prácticas scout, cuyos antecedentes a continuación describiremos.

\section{LA DIFUSIÓN DEL SCOUTISMO}

La JAC promovió la vida scout para sus jóvenes socios. No obstante, vale la pena recordar que liberales y socialistas coincidían en el desarrollo de una juventud sana, fuerte y disciplinada para el mundo del trabajo y la defensa de la ciudadanía. El desarrollo físico, la vida al aire libre y los juegos de asociación se amoldaban a un ideal de individuo respetado y respetable. Una concepción fuertemente ética estaba por detrás de estas organizaciones ya que había que ser sanos, no beber ni caer en banalidades (Lobato; Palermo, 2012, p.45-74).

El scoutismo fue creado en Inglaterra por el general inglés Sir Lord Robert Baden-Powell of Gilwell en el año 1907. Powell, luego de haber participado como comandante de las fuerzas inglesas en el centro de África, escribió un libro, Ideas para explorar. La repercusión de este libro entre los jóvenes fue un detonante para organizar a un grupo de ellos en los pormenores del scoutismo. Fruto de esa experiencia escribió otro libro Scoutismo para muchachos a principios del siglo XX. El primer campamento se realizó en la isla de Brownsen en 1907. Powell moriría en el año 1941 y su legado se expandió a nivel mundial. 
Esta experiencia laica fue tomada por la Iglesia católica en 1918. El sacerdote jesuita Jacques Sevin, luego de interiorizarse en el método, lo vio compatible con la fe y unificó las experiencias católicas que existían desde 1911 en Francia. El scoutismo católico tuvo sus raíces en Argentina a principios de la década de 1920. Como sostiene Pablo Scharagrodsky, la cultura scóutica y la religión encontraron afinidades de tipo ideológico a partir de los años treinta dado que ambas estimulaban el respeto a la jerarquía, la obediencia y la sumisión o cierta concepción sobre la naturaleza del hombre y de tipo moral. Asimismo, los curas jóvenes descubrieron que la práctica scóutica podía ser un buen medio para atraer a la infancia hacia Dios y borrar de raíz algunas diversiones que consideraban asistemáticas, inmorales, crueles e inhumanas (Scharagrodsky, 2008, p.166168). La experiencia de los campamentos católicos de los años veinte reveló la expansión de la oferta de actividades disponibles para realizar durante el tiempo de ocio, y estuvieron más ligados a jóvenes de clase alta.

La primera reunión internacional de scouts católicos se realizó en Londres. Allí, varios jefes de instituciones scout fundaron el secretariado internacional de los scouts católicos, con el beneplácito del papa Benedicto XV. Luego de esta aprobación papal en diversas parroquias y colegios católicos argentinos se profundizó esta práctica que había sido adoptada por Don Bosco y su movimiento de exploradores anteriormente. La experiencia de los Exploradores de Don Bosco se expandió a los colegios religiosos durante las primeras décadas del siglo XX demostrando fuertes preocupaciones vinculadas con la ejercitación corporal masculina, no sólo en el horario escolar a través de sus planes y programas, sino también por fuera del horario escolar obligatorio. Entre las razones por las cuales se crearon sus Exploradores se encuentra la disputa por captar y monopolizar la educación de un sector de la niñez que se hallaba bajo el paraguas ideológico del laicismo dominante en las escuelas. El movimiento hizo hincapié en la regulación y control corporal masculino con una fuerte impronta religiosa. En primer lugar, "honrar, amar y servir a Dios" y, en segundo y tercer lugar, a la "Patria y al Hogar". El enemigo estaba representado por "la masonería que había logrado darle (al scoutismo argentino) un carácter netamente laico”. La exploración 
fue el paso previo a la imposición y a la conquista del cuerpo infantil, a través de ciertos ideales cristianos que regularon un conjunto de problemas, entre los que se destacaron la sexualidad, el placer, el cuidado del cuerpo y la masculinidad deseada (Scharagrodsky, 2009, p.61-62, p.71).

Empero será la reconocida figura del padre Julio Meinvielle quien organizará campamentos de jóvenes en su parroquia. Estos, a diferencia de los realizados en la década del veinte, buscarán conseguir más adherentes al catolicismo entre sectores de clases medias y populares y estuvieron enmarcados en la intensa militancia católica de la década del treinta. En 1936 la experiencia de Meinvielle se expandió fundándose la Unión Scouts Católicos Argentinos (USCA). En 1956 la USCA fue reconocida por la Conferencia Episcopal Argentina como Asociación privada de fieles. La USCA poseía una publicación: la revista Vida Scout, cuyo número citado aquí, de marzo de 1954, llevó en la portada una fotografía del ícono del scoutismo mundial: Robert Baden-Powell. ${ }^{4}$

El scoutismo era definido como un método complementario de educación, en sus formas social, religiosa, moral, intelectual y física teniendo tres puntos fundamentales: Dios, Hogar, Patria, el Prójimo y la ley Scout. Las distintas agrupaciones de la USCA realizaban campamentos para niños y jóvenes. El joven explorador debía cumplir con el código de honor, contribuir a la grandeza de la Nación inspirado en la doctrina cristiana de servir al prójimo, con planteos moralizantes y biologicistas que buscaban apartar al "débil" carente de fortaleza espiritual. El coraje, la valentía y la fuerza eran valores a potenciar y desarrollar. Resta señalar que los campamentos eran organizados por la Delegación de Campamentos, que decidía, año tras año, dónde se realizarían las actividades.

\section{LOS CAMPAMENTOS DE LA JAC}

Los campamentos eran considerados como instancias de regeneración espiritual. Se dividían en Juniores, Seniores y Experimentados. Estructuralmente estaban organizados de la siguiente forma: Asesor, Jefe,

4 Vida Scout, n. 128, p.05, mar. 1954. 
Subjefe; Médico, Secretario, Ecónomo; Encargado Material, Capillero, Jefe de Carpa y Acampantes. En general, todos los campamentos compartían un Administrador general, un cocinero en campamento y un cocinero en las excursiones. En líneas generales, los campamentos se dividían en tres actividades: a) Vida espiritual (misas, comunión diaria, rezo del Rosario y meditación a cargo del asesor); b) Vida Física (tenía como finalidad templar la voluntad y el afán de superación estimulado por las dificultades a vencer; c) Vida Comunitaria (estrechar los lazos de solidaridad para superar las dificultades y estimular la alegría entre los acampantes. Los aspirantes estaban bajo el mando de un delegado.

El sentido de aventura se transfiguraba en la práctica campamentil. Los campamentos se promocionaban apelando a la gesta de los conquistadores, las aventuras de Robinson Crusoe o la de los caballeros medievales. Las novelas aconsejadas por la jerarquía eclesiástica intentaban motivar el espíritu misionero y de aventuras. Como método adoptado para formar las conciencias de los jóvenes en los valores del cristianismo, el scoutismo católico llamaba a superar la mediocridad, purgar el egoísmo y acercar a las clases sociales entre sí para evitar el temido conflicto social. A su vez, propendía al "internacionalismo", no en el sentido de marxista -al cual consideraba uno de los principales enemigos a combatir-, sino promoviendo el amor por la Patria y el sentido de fraternidad entre los pueblos.

¿Qué se perseguía con esto? Los campamentos eran caratulados como una instancia de "verdadera libración" para la juventud, un "oasis" en el mundo moderno. Así lo reflejaba el diario católico Antorcha: "En un mundo de asqueante mediocridad, repleto de hombres de cerebros cubiformes, que viven en casas cubiformes y que piensan y actúan con ideas cubiformes, los jóvenes nuevos se encuentran ahogados en esas ciudades cuadradas, tristes y pequeñas y sienten sed de llanuras inmensas, de cumbres incontaminadas, de cielo puro, de grandeza espiritual, de alegría”. La juventud católica era escenificada como la renovación de la Patria, destinada a una misión histórica que pretendía manifestarse contra la desilusión producida por las dificultades promocionadas por 
una mentalidad moderna que avanzaba sin detenerse en las advertencias morales del catolicismo.

Las publicaciones apelaban a la deseada fortaleza masculina "Una juventud viril para estos tiempos fuertes", al destino, la lucha, los imperativos y la voluntad: "Sepan, pues, los apáticos sin luchar que inexorablemente deben reformarse o perecer". Se aspiraba que el joven de JAC fuera "un verdadero hombre", que sus compañeros de ambiente de trabajo o estudio lo consideraran como tal, "no a uno de esos apocados, de esos aniñados que no valen nada". Ese "verdadero hombre" con virtudes católicas y nacionales tendría que tener temple, ser seguro, tener coraje y saber enfrentar los inconvenientes de la vida aprendidos a partir de la resolución de conflictos que le presentaba el medio natural. Se propiciaba una definición esencialista de "lo masculino".

Todas estas máximas inculcaban la misma lógica prometeica de la modernidad en pos de la redención: "Morir por la Patria es morir por algo muy grande, amar a la Patria es amar un bien casi divino", señalaba la editorial Conquista en 1949. Es decir, la Patria se asociaba con la imagen misma de Dios. Dentro de esta lógica, Jorge Taussig, el Delegado superior de Aspirantes, interpelaba al apostolado a conocer la Patria, su geografía y costumbres cristianas, ya que con el correr de los años la población había olvidado la grandeza del territorio. El conocimiento de la geografía, la historia y del catolicismo colaboraban a la construcción de la identidad nacional y católica. Por lo tanto, la JAC debía devolverle el "recio, duro, macizo espíritu colonial" extraviado con las estructuras liberales instauradas en el siglo XIX (Bertoni, 2001, p.17-80). Había que salir "por la Patria a restaurarla más cristiana y más argentina". Se buscaba su basamento en la hispanidad católica colonial. En este clima de ideas, los campamentos se realizaban en lugares "históricos" con el objetivo de estimular el conocimiento de los acontecimientos bélicos que se consideraban fundantes de la argentinidad.

En 1946, los aspirantes de la JAC realizaron su campamento en San Fernando, en la Quebrada de Escoipe (Salta) en los lugares donde transcurrió la "Guerra Gaucha”. La intención de reconstruir la aventura de 
soldados enfrentando los desafíos que les planteaban la naturaleza y los ejércitos hostiles implicaba un ejercicio de la imaginación en el cual se intentaba trasladar los acciones que debieron haber realizado aquellos jóvenes para combatir a los "enemigos de la nación" a la experiencia de los actuales jóvenes para enfrentar a los "enemigos de la cristiandad". El conocimiento vivencial del espacio geográfico y de la historia garantizarían la construcción de la nacionalidad. Estos sentidos anclaban en los orígenes del scoutismo a fines del siglo XIX. Las representaciones sobre la naturaleza en el movimiento scout estuvieron ligadas con el régimen de poder que el imperialismo y el colonialismo europeo instalaron en distintas regiones del planeta. En otro plano, el scoutismo contribuyó a diagramar las nuevas identidades nacionales.

El cuerpo y el deporte en el cristianismo no eran contradictorios. La idea era generar en los niños y jóvenes el dominio sobre sí mismos, el sosiego y la búsqueda de la templanza. Los juegos de asociación, la vida al aire libre y el contacto con la naturaleza permitirían el traspaso de lo sagrado a lo profano, es decir, del mundo terrenal al mundo divino. Este tipo de acciones tienen un ejercicio ritual ligado a lo sagrado. Así, los campamentos se homologaban a una experiencia religiosa vivida en comunidad. Detrás de la contemplación del sol, el agua, las plantas, los animales y las montañas se suponía que subyacía la búsqueda del autoconocimiento del espíritu y el autocontrol de las conductas desviadas.

Para auscultar esa realidad por medio de la vida scout, el organismo técnico de la Junta Central aconsejaba que los participantes desarrollaran las pruebas de "observación" y de "stalking". La primera residía en el carácter ya que, según el editorial de Vida Scout, el ejercicio metódico de la observación modifica el carácter, desarrolla la inteligencia y le confiere al observador una amplia seguridad en sus juicios. El segundo estaba entroncado con la observación directa de animales salvajes y de la naturaleza en toda su plenitud entendiendo que en esa instancia se manifiestan las cualidades de paciencia, sagacidad y valor de un scout. Seguir cauteloso a un animal sin ser visto y estudiar sus hábitos; era una actividad regenerativa que "llena el alma de alegría". El "tracking" (arte de reconocer y seguir una pista) era otra de las cualidades que debía aprender un scout. Para 
internalizarse en el oficio la revista Vida Scout recomendaba ejercitarse con pistas artificiales, preparadas con pedazos de papel, hojas o ramas. ${ }^{5}$

La vida de los centros durante las vacaciones fluía en los campamentos. Según el Boletín en Jefe - publicación de la ACA- las vacaciones constituían una inundación de fútbol, cine, mordisqueo de uñas, bicicleta. ¿Qué tenía que hacer el jefe en vacaciones?: junto con el aumento de las diversiones, debía aumentar las comuniones, las risas y las visitas parroquiales. Los campamentos eran una de las opciones para vivir las vacaciones en la piedad cristiana y moldear el carácter bajo el molde hegemónico imperante de las conductas esperada para la masculinidad.

De acuerdo con la publicación Servir - órgano de los jefes de la JAC -, los campamentos eran para varones con "espíritu recio, no para niños bien". La intención de captar nuevos adherentes provenientes de otras clases sociales fue una constante en los años treinta y cuarenta. El catolicismo suministraba una usina ideológica que alentaba el control del conflicto social y se buscaba que allí pudieran germinar ideas y futuras acciones que apuntalaran el statu quo. Como telón de fondo hay que recordar que esta preocupación en el mundo de los trabajadores urbanos tuvo como resultado la creación de la Juventud Católica Obrera en 1940 y su proyecto integrista de la Iglesia Católica basado en la organicidad social, las jerarquías establecidas y la armonía de clases y en el que los individuos están delimitados por deberes y responsabilidades (Blanco, 2014, p.219).

Según el Boletín Informativo y Diario del Campamento de Juniores realizado en Bariloche en 1954, los campamentos realizados por la JAC apuntaban a evitar que los socios se desbarrancaran en la "insensibilidad del pecado". Es decir, que en sus medios se naturalizara el mal, en sus múltiples manifestaciones, perdiendo su capacidad de apóstol y cayendo en una suerte de "aburguesamiento". Por lo tanto, la vida al aire libre, en la montaña o en el mar, implicaba superación y convivencia fraternal. El perfil del joven scout católico debía nutrirse de la piedad, la abnegación y alegría. Con la tríada "Entusiasmo, propaganda y mover el ambiente"

5 Vida Scout, n. 128, p.07, mar. 1954. 
se llamaba a los militantes a saldar los inconvenientes que encorsetaban el desarrollo del scoutismo católico: uno de índole material, y el otro, la falta de interés de los compañeros para concurrir a ellos. Para vencer la apatía los fieles debían convencerse a sí mismos del sentido redentor y purificador que tenía el contacto con la naturaleza.

Los cupos para realizar el campamento se abonaban con antelación con el 50\% del importe para reservar los pasajes del ferrocarril (único medio de locomoción para arribar). En la organización había un encargado de campamentos junto con el delegado arquidiocesano de aspirantes. Los campamentos a Bariloche se extendían por doce días. El de 1951 tuvo como destino Colonia Suiza, sobre el lago Moreno y tenía la siguiente programación: Escalar los Cerros Goye y López, Visita a los Ventisqueros del Cerro Tronador, recorrido alrededor de los lagos; escalar el Cerro Catedral. Según consta en la Circular Especial de "Campamentos" de agosto de 1955, los campamentos de ese año contaron con un gran apoyo por parte de los socios de la JAC, dado que setenta efectivos y setenta aspirantes participaron de los mismos en San Carlos de Bariloche, y cuarenta y tres efectivos y ciento veinte aspirantes concurrieron a los organizados en época de carnaval, en las inmediaciones de Buenos Aires. Resta señalar que la cultura campamental podía despertar las convicciones por el sacerdocio. De los cincuenta y seis aspirantes que participaron en el campamento realizado en Tucumán en marzo de 1958, dos ingresaron al seminario inspirados en la experiencia vivenciada. En rigor de verdad, la cultura campamental encontraba su correlato en las experiencias de socialización que aplicaban en Europa y tenía como finalidad incorporar a los jóvenes al molde de una ciudadanía deseada y sostenida por las directrices ideológicas del catolicismo.

\section{OCIO, TIEMPO LIBRE Y SEXUALIDAD}

Norbert Elías y Eric Dunning desarrollan un marco teórico para estudiar el ocio. Según ellos habría que distinguir las relaciones entre tiempo libre y ocio. El tiempo libre se refiere al trabajo ocupacional, y en sociedades como las nuestras, sólo una parte de ese tiempo puede dedicarse a las 
actividades recreativas. Los autores señalan que el tiempo libre puede reducirse en cinco esferas distintas que se entremezclan trabajo privado o administración familiar; descanso como fumar, tejer y vagar en los pensamientos; satisfacción de las necesidades biológicas como beber, alimentarse, tener sexo y dormir; sociabilidad entendidas como viajes, excursiones o visitar a amigos; clase de actividades miméticas o de juego, ir al teatro o a un concierto, a las carreras, al cine; cazar, pescar, escalar montañas, apostar, bailar y ver la televisión. De acuerdo con esta tipología no se puede dedicar al ocio una buena parte del tiempo libre, resultando inadecuada la polarización entre ocio y tiempo libre pues todo, el tiempo no invertido en trabajo asalariado, todo el tiempo libre puede ser destinado a actividades recreativas. El ocio es uno de los pocos reductos en los que, aún en las sociedades industrializadas, pueden los individuos buscar cierta excitación emocional e incluso mostrarla hasta cierto punto de una forma socialmente regulada (Elías; Dunning, 1992, p.89, p.149).

Si tomamos esta definición, en las publicaciones de la JAC no existe tal distinción entre ocio y tiempo libre. Ambos son utilizados como sinónimos. El ocio y el tiempo libre para la ACA y la JAC constituían un peligro en sí mismo. Por un lado, el tiempo libre generado por la vida moderna y las diversiones - como el cine, la playa, los espectáculos frívolos - habría generado una devoción desmesurada entre la juventud y un incremento en los consumos culturales. Por otro lado, los vínculos familiares, según la visión de la ACA, aflojaban desmesuradamente: "El hogar no es mucha veces más que una pensión: se come y se duerme en él, se divierte y se trabaja fuera de él".

Con respecto al cine, existía la posibilidad de que el junior o aspirante sea atacado por esa "enfermedad". Temáticas como el adulterio, el divorcio, la sexualidad, la exposición de los cuerpos, eran condenadas por la jerarquía eclesiástica. Como forma de diversión moderna, el arma apostólica para contrarrestarlo era la calificación moral de las películas. En esa cosmovisión del mundo, los espectáculos cinematográficos habrían pervertido las costumbres y el aumento de los vicios. ${ }^{6}$

6 El Cine. Antorcha, n. 33, p.18-19, 1939. 
Los meses de vacaciones eran los más peligrosos para la vida de las secciones Internas de la JAC. Se instaba a que los delegados y aspirantes enfrentaran las amenazas de la modernidad realizando reuniones en ese periodo, como concurrir a la parroquia más cercana de veraneo, mantener correspondencia entre ellos y estimular la lectura de la literatura recomendada por el INDEX: tales como las obras de Tom Playfair, Julio Verne, Per Reil. El INDEX era un catálogo de libros prohibidos por la Santa Sede quien arbitraba una colección de reglas generales de prohibición (Cammarota, 2015, p.219).

En vacaciones se estimulaba la continuidad formativa y pedagógica de los centros. Las vacaciones, según el Boletín del Dirigente, se han transformado de medio en fin. No se recupera energía en las vacaciones, sino que se agota el carácter con ellas debido al placer sin medida y la vida frívola. Por añadidura, los contrapesos espirituales ayudaban a no desbarrancar emocionalmente. La ociosidad traía aparejada un incremento de la vida imaginativa descontrolada producto de la observación inconsciente y no metódica. Por lo tanto, subyacía un peligro inminente que rayaba con el desorden erótico generando un descenso general de la vida cristiana del Aspirante.

La cultura scout fue netamente varonil. La alteridad sexual encarnada en las mujeres jugaba otro rol dentro del catolicismo. Se tomaba el modelo de la madre abnegada, en pos del sacrificio y la sumisión a los designios sociales culturalmente establecidos: ser buena madre y esposa. Cabe destacar que la ACA poseía su Liga de Damas Católicas desde la década de los treinta. Desde su boletín, Anhelos, se inculcaba que el apostolado de la mujer católica estaba a las órdenes de los dignatarios de la Iglesia y era esencialmente un apostolado eucarístico, es decir, tenía como misión propagar en los fieles las razones de la eucaristía y era obligación de las madres católicas la ejecución de las normas para la primera Comunión de sus hijos/as. ${ }^{7}$

La maternidad era una de las metas sagradas de las mujeres católicas como en la sociedad burguesa-liberal. A partir de la igualdad ante los

7 Anhelos, n. 1, p.33, 1934. 
ojos de Dios de todos los seres humanos se pautaba la diferencia sexual en el mundo terrenal. Al igual que en el sistema capitalista, la ACA delimitaba el rol de las niñas y mujeres en la vida social enarbolando una supuesta naturaleza "femenina" y "masculina”. Las misiones de las mujeres, tales como la maternidad, la sumisión al varón y al matrimonio y el cuidado de los hijos/as, se veía amenazada por la radio, el cine y la primera juventud. Según declamaba el Boletín Mensual de la Liga de Damas Católicas, la edad más peligrosa para las niñas era alrededor de la pubertad. La publicación alegaba que las amigas eran el primer peligro para las costumbres de la niña, por lo tanto, las madres debían informarse de las costumbres de esas niñas, de lo que veían y oían en sus casas para evitar conductas por fuera del modelo heterosexual. Las cintas cinematográficas como Tarzán entrañaban un sublime peligro para la moral de la niña cristina: la naturaleza. Si bien el scoutismo, como vimos, promovía el contacto con la naturaleza para el desarrollo de una virilidad masculina contenida a partir de los campamentos; la ausencia de dicho control en los eslabones escenográficos de las películas constituía un peligro por la falta de regulación e intermediación en la interpretación de dichas imágenes para las mujeres. Por ejemplo, en la película Tarzán las espectadoras eran atraídas por las escenas salvajes de la selva y de tantos otros trucos que engañaban, según el artículo, a las subjetividades juveniles. En el film el hombre se despojaba de toda su espiritualidad y se lo presentaba transformado en una bestia que vivía de acuerdo a sus instintos. Se recomendaba a las madres vigilar la elección del vestuario de sus hijas y, sobre todo, rechazar aquellos trajes de baño que mostraran las desnudeces de las espaldas; ya que sus conductas eran las culpables del deseo sexual masculino. Acorde con las resoluciones del Episcopado Argentino de 1933 se estableció que la conducta cristiana se veía alterada por la "promiscuidad de sexos en las piletas públicas de natación y en ciertas diversiones veraniegas en que el vestido es completamente inadecuado para estar fuera del agua". Se rechazaban los concursos de bellezas y los concursos gimnásticos femeninos. Por otro lado, se exhortaba a la Liga de Damas Católicas a impedir el ingreso al templo de aquellas mujeres que se presentaran 
con el pecho y los brazos descubiertos negando la entrada a las escuelas católicas de aquellas niñas con vestidos poco decentes.

Esta ingeniería moral en pos de controlar las voluntades que contenían las posibles pasiones corporales se debilitaba ante la falta de ejercitación de las lecciones que componían la tarea del estudio dentro de la parroquia y la ausencia de una conducta cristina que buscaba controlar al otro sexualizado, pensado a las mujeres desde una matriz diferencial. En los ratos de ocio o en las vacaciones, estas tentaciones o atracciones corporales podían emerger. Por lo tanto, la parroquia tendría un rol sustantivo para someter las actividades del fiel y para evitar los potenciales escenarios descontrolados se implementó el Grest (Grupo Estival).

\section{Amistad y RELIGIOSIDAD}

En el verano las secciones de Aspirantes de la Ciudad de Buenos Aires se transformaban en el Grest, es decir, reuniones de amigos que mantenían cierta continuidad con la formación religiosa de las parroquias: "Pues entonces ¿qué esperamos? ¡A transformar la Sección! A convertirla en el Grest, en el grupo estival, que no es otra cosa que la vida de la Sección a RITMO DIARIO Y AL AIRE LIBRE! (...) el grupo también se convierte en LA PATRULLA, ¿y el JEFE?, pues el Jefe se convierte en el Patrullero máximo en el DE LA PATRULLA. El Grest era una promesa de acción y una declaración de guerra al ocio considerado pernicioso".

El Grest estaba divido en tres momentos. El primero era La Hora de la Luz, que se iniciaba temprano a la mañana con la misa, continuaba con la Meditación "para meter en la cabeza del Aspirante un pensamiento que lo tenga vigilante contra el mal, durante todo el día" y luego cada aspirante se retiraba a casa. El segundo momento era La Hora del Sol, considerado como uno de los peores peligros del alma ya que durante el mediodía el ocio gana terreno en vacaciones y trata de "enredar la voluntad del muchacho, favoreciendo el desarrollo de los pensamientos impuros, de las tentaciones". Para vencer este momento el muchacho

8 Conquista, n. 54, p.05, 1951. 
tenía que encontrarse con amigos sin ofender a Dios, con juegos al aire libre que evitasen la intimidad. No obstante, se recomendaba variar las actividades físicas, ya que existía el temor de que la práctica de deportes colectivos favoreciera la homosexualidad. Por lo tanto, el estímulo de otras actividades, con diferentes jóvenes y con distintas características podría ser un antídoto para evitar las "perversiones sexuales" (Ramacciotti; Valobra, 2014, p.195-216). Los paseos debían realizarse en un clima de entusiasmo. Por último, La Hora de las Estrellas presentaba el peligro de la "promiscuidad de las diversiones nocturnas, las escenas de poca moralidad o de inmoralidad completa, que se observa por las calles, plazas y jardines". Por lo tanto, los jóvenes debían concurrir a la sede y al patio parroquial para desarrollar juegos en el patio y plegarias nocturnas antes de retirarse a sus hogares a dormir.

El delegado cumplía un rol esencial ya que durante las vacaciones tenía que consolidar la vida de la sección tratando de mantener el entusiasmo, el cumplimiento y la vida activa de sus aspirantes dentro del dogma católico. Las directivas para el verano constaban de tres partes: vida espiritual, estudio y acción. La primera estimaba que la vida de piedad debía intensificarse ya que el aspirante durante el verano tenía un enorme tiempo libre hallándose frente al peligro de la pereza y el ocio. Con respecto al estudio se recomendaba estudiar la Santa Misa. Con la Acción se instaba a usar el tiempo libre para la realización de campeonatos dominicales - olimpíadas relámpago, paseos de una tarde o un día o campamentos - . Todos los aspirantes que salieran de veraneo debían estar munidos de la Credencial de Tránsito que se adquiría en el Consejo, a los efectos de poder asistir a las reuniones de la parroquia más cercana a su domicilio de veraneo.

La Delegación Arquidiocesana de Aspirantes implementó una serie de normas generales para delegados de aspirantes que apuntaban a consolidar la praxis del scoutismo católico. La primera era el Trabajo Personal del Delegado. Éste tenía que conversar con los aspirantes haciéndoles conocer los beneficios del campamento tanto en el orden espiritual, físico y el conocimiento de la geografía de la Patria. Otro de las obligaciones era visitar a los padres de los aspirantes para ponerlos 
al tanto del funcionamiento del Campamento. La segunda norma era el Trabajo en la Sección: la propaganda (exponer el programa del Campamento a los Aspirantes, acompañado de fotos o películas), reunir el cenáculo para crear un clima de campamento; confeccionar varios afiches para la cartelera con los datos del campamento y enseñar cantos cuyo cancionero se podía adquirir en el Consejo a una suma de 3 pesos. Otro de los puntos era programar la financiación con rifas y festivales y organizar una caja de ahorro.

\section{EL TURISMO COMO VEHÍCULO DE CRISTIANIZACIÓN}

¿Hasta qué punto se cumplían todas estas acciones? ¿Cuántos jóvenes estaban dispuestos subjetivamente para cumplir con el régimen religioso dispuesto por el Grest? La respuesta no es sencilla. Sin embargo, en un contexto en cual los sectores populares no disponían de los recursos suficientes para veranear, los campamentos organizados por las JAC podrían resultar ser una opción viable para alejarse de los centros urbanos. En la publicación Conquista - Boletín para los Aspirantes de Buenos Aires - se insistía que los campamentos eran la solución para los jóvenes que en vacaciones querían "hacer turismo" se intentaba buscar adhesiones a partir de los valores que trataban combatir. Vacacionar era sinónimo de hedonismo y de una moral más relejada; empero el término fue usado para lograr más militantes católicos. El juego y los deportes se promovían entre los estudiantes del ciclo medio como un aliciente para acercar a un mayor número de fieles a la Iglesia. Promocionados como "turismo de hombres" en los campamentos se podía forjar el coraje y vencer a la naturaleza con "fuerza, destreza y voluntad". Brindaban la oportunidad de auscultar las entrañas del suelo argentino y vivenciar esa naturaleza, que muchos jóvenes apreciaban solo en las imágenes de los manuales de textos escolares, en las revistas o en las descripciones noticiosas de los programas radiales.

¿Conspiraba contra la realización de estos campamentos la rígida estructura disciplinante de la cultura católica? En otro nivel ¿fueron masivos dichos campamentos? ¿Hasta qué punto mediando la década 
de los cuarenta los jóvenes de los sectores populares cuyos padres habían mejorado sus ingresos salariales no comenzaron a elegir un destino turístico propio? A ciencia cierta, los interrogantes no tienen una respuesta inmediata. Lo cierto es que, como señala Elisa Pastoriza (2011, p.81-89), en un contexto en que se perfilaba el nacimiento de un horizonte turístico masivo impulsado por el peronismo - Mar del Plata cuyo modelo hedonista se oponía a la idea del contacto con la naturaleza y la tranquilidad en desmedro de la diversión y el entretenimiento, en la Argentina comenzaron a tener visibilidad lugares que, al margen de sus bellezas naturales, se identificaron por sus climas especialmente benéficos para la cura de ciertas enfermedades emergiendo las ideas de un turismo saludable, gracias el desarrollo de una creciente infraestructura (hoteles y caminos). Un país más vertebrado e integrado por la expansión de la radio que llevaba las noticias a los rincones más alejados del país ayudó a fortalecer, junto con el crecimiento de los centros urbanos, el proceso de homogeneización cultural que venía siendo promovido por la escuela y el servicio militar (Pastoriza; Torre, 2002, p.269). Sobre este escenario de crecimiento y modernización, la capacidad regeneradora de la naturaleza, el aislamiento de las montañas y el distanciamiento de la vida urbana permitían alejar a los jóvenes de las posibles infracciones morales a las que podían estar expuestos en las playas donde concurrían adolescentes de ambos sexos.

A diferencia de los campamentos de los años veinte, las playas se descartaban como destino turístico para los campamentos católicos ya que las temperaturas altas, la cercanía al mar y el uso de vestimentas más livianas, dejaban los cuerpos visibles y podían despertar las pasiones sexuales y "enfermar" el cuerpo católico. Diversas publicaciones católicas advertían de este peligro latente. Los lugares escogidos por la JAC servían para "encontrarte a ti mismo, en el silencio de las nieves eternas o en el murmullo de un río que corre ligero, para volver más fuerte, más hombre, más compañero (...) y también un poco más bueno y eficaz en tu diaria labor". Escalar montañas era una actividad promovida ya que esa destreza física favorecía la hombría, el valor, el vigor, la fuerza y el coraje ya que el hombre "vence con su habilidad y a fuerza de corazón la naturaleza". 
Los campamentos eran promocionados como un espacio de recreo ante la intensa actividad a la que estaban expuestos los jóvenes de la JAC durante el año “aspirantil”. Más allá de forjar la espiritualidad y el carácter, también se promocionaban como un dispositivo de atracción para la deserción juvenil de la organización que se estaba produciendo a fines de la década de 1950. Por ejemplo, el Plan de Labor del año 1954 diseñado por la Delegación Arquidiocesana de Aspirantes bregaba por la "asociación de masa", es decir, que las Comisiones Directivas de los Centros debían promover, donde no existiese, una organización de este tipo con distintas edades y niveles educativos. El problema radicaba en "la gran cantidad de chicos que habiendo recibido la Primera Comunión se han alejado de la Parroquia y de los que formando parte de nuestras Secciones de Aspirantes no reúnen las condiciones necesarias para la ACA".

La vida campamentil brindaba herramientas para que los jóvenes intentaran anestesiar sus deseos sexuales y neutralizar los estereotipos que imponían la modernidad, el consumo y las ideologías de izquierda. También ambicionaron buscar más adhesiones al catolicismo provenientes de sectores sociales medios y bajos y lograr asentar los valores de la cristiandad en base a una experiencia de vida concreta que ligaba lo sagrado con la naturaleza, el ascetismo y la disciplina jerárquica, entre otras cosas. En este sentido, los campamentos se presentaban como una opción para los sectores populares con escasos recursos para vacacionar. Sin embargo, si bien los socios de la JAC aumentaron en la década del cuarenta, los campamentos parecen no haber contado con la masividad deseada por la jerarquía eclesiástica. Esto marcaría una diferenciación con el crecimiento del scoutismo laico en las décadas precedentes. Hasta el momento no hemos encontrado datos cuantitativos que nos permitan realizar una comparación fehaciente. Quizás tendríamos que estudiar, en una futura investigación, hasta qué punto la rígida estructura de la JAC, sus prácticas rituales y esquemas disciplinarios se constituyeron en un obstáculo para atraer a los jóvenes a una mayor cantidad de jóvenes. Hay que señalar que a fines de la década de 1950, las tasas de afiliación de la JAC estaban en franca caída y el recambio generacional de sus dirigentes era casi nulo (Acha, 2010, p.07-42). A este estancamiento 
generacional cabe agregar que los campamentos no sufrieron modificaciones en cuanto a su estructura, funcionamiento y finalidad durante los años peronistas.

Pero más allá de estas consideraciones, la experiencia del scoutismo católico entre las décadas de 1940-1960 fue uno de los tantos espacios de socialización juvenil que configuraron determinadas identidades y que habilitaron una suerte de "pugna" entre el Estado laico y sus instituciones como la escuela, la Iglesia o los partidos políticos o las familias. Los campamentos aspiraron a un objetivo: moldear un determinado "ser joven" masculino como metáfora del dinamismo, fortaleza y virilidad y, en contraposición, una "ser joven" femenina pasiva; relegada a la vida doméstica y constreñida a la reproducción y al cuidado.

\section{CONSIDERACIONES FINALES}

La cultura scout católica asentó un determinado modelo de masculinidad y fue una experiencia protagonizada por varones. Si bien Naír Mercedes Fernández Blanco de Gowland fundó la Asociación de Guías Argentina en 1953 intentando imitar la experiencia de las Bandeirantes (denominación de las niñas scout en Brasil) e hizo algunas reuniones en su domicilio particular; el único registro de campamentos de mujeres fue estudiado por Laura Méndez, quien explora la experiencia de las girls scouts "Tambor de Tacuarí" en 1937. Ellas visitaron Bariloche y continuaron su viaje hasta el hito fronterizo de Puerto Blest, para encontrarse allí con un grupo de niñas scouts chilenas (Méndez, 2014, p.15). No obstante esta solitaria experiencia de campamento laico, no existen registros, hasta el momento, de campamentos de mujeres católicas. Esto coincide con la mirada que, según Miranda Lida, tenía la ACA, en su rama femenina, con respecto a la nula importancia otorgada a los deportes y a los campamentos para las mujeres. La concepción del espacio público como masculino y el privado como femenino dialogaba con los ideales impuesto por la vida campamentil.

La cultura católica reafirmó los estereotipos de género y los campamentos auspiciados por la JAC estimularon un conjunto de valores y 
conductas ligado a la masculinidad: fortaleza, valentía, organización, astucia, coraje, seriedad, mansedumbre y contemplación. Valores aprendidos a partir del contacto y del conocimiento de la geografía nacional y, que a futuro, se consideraban vitales para la construcción de la identidad católica y nacional de los futuros ciudadanos. El ejercicio físico, no excesivo y variado, el estudio del evangelio, el rezo, la práctica de la contemplación de la naturaleza, la vida en comunidad bajo reglas estrictas permitirían domeñar las novedades biológicas de los cuerpos, las tentaciones del placer sexual y además brindarles habilidades para vivir en una sociedad reglada y jerárquica. En este modelo de masculinidad, ideal e idealizada, se contraponía el rol de la mujer relegada al ámbito doméstico, educada para su rol de futura madre. Todas sus actividades públicas estuvieron condicionadas desde su rol doméstico y su función reproductiva.

\section{REFERENCIAS BIBLIOGRAFICAS}

ACHA, Omar. Tendencias de la afiliación en la Acción Católica Argentina (1931-1960). Travesía - Revista de Historia Económica y Social, vol. 1, n. 12, p.07-42, 2010.

BALLENT, Anahí. Las huellas de la política. Vivienda, ciudad, peronismo en Buenos Aires, 1943-1955. Buenos Aires: Universidad Nacional de Quilmes, 2006.

BERTONI, Lilia Ana. Patriotas, cosmopolitas y nacionalistas. La construcción de la nacionalidad argentina a fines del siglo XIX. Buenos Aires: Fondo de Cultura Económica, 2001.

BISSO, Andrés. Scouts sin scoutismo. Los artículos de Ángel M. Giménez y la posición de los socialistas argentinos frente a la institucionalización estatal del scoutismo (1918-1920). Anuario del Centro de Estudios Históricos "Prof. Carlos S. A. Segreti”, año 4, n. 14, 2016.

BLANCO, Jésica. Las distintas juventudes de la Iglesia en Argentina a mediados del siglo XX. Los casos de la Juventud de Acción Católica y la Juventud Obrera Católica. Letras Históricas, n. 4, p.139-160, 2011.

BLANCO, Jésica. Ser jocista en la Argentina de mediados de siglo XX. La construcción de identidades etarias, confesionales y laborales en la 
Juventud Obrera Católica. Revista Mundos do Trabalho, vol. 6, n. 11, p.207-223, 2014.

CAMMAROTA, Adrián. "Somos bachiyeres". Juventud, cultura escolar y peronismo en el Colegio Nacional Mixto de Morón (1949-1969). Buenos Aires: Biblos, 2014.

CAMMAROTA, Adrián. 'Soldados de Cristo Rey'. Notas sobre la educación y la cultura del apostolado en la Juventud de la Acción Católica. Revista de Estudios Sociales Contemporáneos, vol. 1, n. 12, p.209-228, 2015.

ELÍAS, Norbert; DUNNING, Eric. Deporte y ocio en el proceso de civilización. Buenos Aires: Fondo de Cultura Económica, 1992.

LIDA, Miranda. Catolicismo y sensibilidad antiburguesa. La Iglesia Católica en una era de desarrollo, 1955-1965. Quinto Sol, vol. 16, n. 2, p.01-20, 2012.

LOBATO, Mirta; PALERMO, Silvana. Del trabajo a las calles. In: LOBATO, Mirta (ed.). Buenos Aires. Manifestaciones, fiestas y rituales en el siglo XX. Buenos Aires: Biblos, 2012. p.45-74.

MÉNDEZ, Laura. Flor de Lis. Scoutismo y cultura física en clave femenina. 1910-1930. $10^{\circ}$ Congreso Argentino y $5^{\circ}$ Latinoamericano de Educación Física y Ciencias, La Plata, 2013.

MÉNDEZ, Laura. Moldear el carácter, forjar la nación. El Tiro Federal y el Scoutismo en la Norpatagonia de las primeras décadas del siglo XX. In: SCHARAGRODSKY, Pablo (comp.). Miradas médicas sobre la 'cultura física' en Argentina (1880-1970). Buenos Aires: Prometeo, 2014. p.50-67. PASTORIZA, Elisa. La conquista de las vacaciones. Breve historia del turismo en la Argentina. Buenos Aires: Edhasa, 2011.

PASTORIZA, Elisa; TORRE, Juan Carlos. La democratización del bienestar. In: TORRE, Juan Carlos (dir.). Nueva Historia Argentina, tomo VIII, Los años peronistas (1943-1955). Buenos Aires: Sudamericana, 2002. p.260-312.

RAMACCIOTTI, Karina; VALOBRA Adriana. 'Peor que putas.... Tríbadas, safistas y homosexuales en el discurso moral hegemónico del campo médico, 1936-1954. In: BARRANCOS, Dora; GUY, Donna; VALOBRA, Adriana (eds.). Moralidades y comportamientos sexuales, Argentina, 1880-2011. Buenos Aires: Biblos, 2014. p.195-216. 
SCARZANELLA, Eugenia. El ocio peronista: vacaciones y "turismo popular" en Argentina (1943-1955). Entrepasados, n. 14, p.69-884, 1998.

SCHARAGRODSKY, Pablo. El scautismo en la educación física bonaerense: Argentina o acerca del buen encauzamiento varonil (1914-1916). Revista Brasileira de Ciências do Esporte, vol. 29, n. 3, p.155-171, mayo 2008.

SCHARAGRODSKY, Pablo. El scautismo en la Educación Física Bonaerense o acerca del buen encauzamiento varonil (1914-1916). In: AISENSTEIN, Ángela; SCHARAGRODSKY, Pablo (comps.). Tras las huella de la Educación Física Escolar Argentina. Cuerpo, género y pedagogía, 1880-1950. Buenos Aires: Prometeo, 2006. p.135-158.

SCHARAGRODSKY, Pablo. En el nombre del Padre, del Hijo y del Espíritu Gimnástico: Prácticas corporales, masculinidades y religiosidad en los Exploradores de Don Bosco en la Argentina de principios del Siglo XX. Educar em revista, vol. 1, n. 33, p.57-74, 2009.

SCHARAGRODSKY, Pablo; CORNELIS, Stella Maris. Modelar la masculinidad cristiana: prácticas corporales en los Exploradores Argentinos de Don Bosco (primera mitad del siglo XX). In: RODRIGUEZ, Ana María (comp.). Estudios de historia religiosa argentina. Rosario: Prohistoria, 2013. p.119-146. 